\title{
The first Dexiinae from Mauritius: the description of a new species of Pandelleia Villeneuve, 1907 (Diptera, Tachinidae)
}

\author{
Marcelo Domingos de Santis ${ }^{1,2}$ \& Silvio Shigueo Nihei ${ }^{1,3}$ \\ 1 Universidade de São Paulo (USP), Instituto de Biociências (IB-USP), Departamento de Zoologia, \\ Laboratório de Sistemática e Biogeografia de Insecta. São Paulo, SP, Brasil. \\ 2 ORCID: http://orcid.org/0000-0003-4949-6433.E-mail:mrclsantis@gmail.com \\ 3 ORCID: http://orcid.org/0000-0002-6887-6282. E-mail: silvionihei@gmail.com
}

\begin{abstract}
A new species of the Afro-Palearctic genus Pandelleia Villeneuve, 1907 (Diptera: Tachinidae), P. crosskeyi sp. nov., from Mauritius is described. This is the first Dexiinae to be described from Mauritius. In addition, this new species corresponds to the ninth species for this genus, and the third in the Afrotropics. The main external features that distinguish it from the other species in this genus is the abdomen that lacks the pair of small, round and dark brown spots, vein $M$ ending in $R_{4+5}$ at a $90^{\circ}$ angle, and female with dark brown scutellum.
\end{abstract}

Keywords. Afrotropical; Dexiinae; Description; Dufourini; New species.

\section{INTRODUCTION}

Mauritius, along with the other main islands of Reunion and Rodrigues, compose the archipelago of Mascarenes. The history of Mauritius, similar to the islands of Réunion and Rodrigues, has been an endless series of ecological disasters and species extinctions (Thébaud et al., 2009); for instance, the extinct Dodo, the universal symbol of human-caused species extinction on islands, once lived on Mauritius. The highly endemic tachinid fauna of the region, currently listed among the world's top Biodiversity Hotspots (Thébaud et al., 2009), currently includes 15 species scattered among 11 genera of Tachinidae placed in Exoristinae or Tachininae (O'Hara et al., 2020), but none from the remaining subfamilies of Phasiinae or Dexiinae.

Pandelleia Villeneuve, 1907, is a Dexiinae genus with Afrotropical and Palearctic distribution, and it is currently placed in the tribe Dufouriini (Herting \& Dely-Draskovits, 1993; O'Hara \& Cerretti, 2016). Pandelleia is a poorly known genus, with some species being recognized only by the holotype. This genus includes eight species (Table 1), with $P$. sexpunctata (Pandellé, 1896) as type species. Mesnil (1975) revised the genus and provided a key to species in which he considered the Afrotropical Afrophasia, Curran, 1939 (now a synonym of Pandelleia), with the Palearctic species P. pschorni Mesnil, 1963, as a distinct genus. Mesnil stated that the study of Pandelleia is very difficult because the species are very rare and some are only known from males (e.g., P. ornata (Rohdendorf, 1923)), while others are known only from females (e.g., P. pilicauda Mesnil, 1975). The biology of the genus is little known, but some species have been recorded parasitizing species of Curculionidae (Crosskey, 1984; Thiem, 1922) and Chrysomelidae (Shima, 2015).

In the present study, we describe the first Dexiinae from Mauritius, a new species of Pandelleia previously identified and recognized as new by the late Dr. Roger Ward Crosskey. He left this undescribed species at the NHMUK collection. Furthermore, in his work on tachinids from tropical and southern Africa (Crosskey, 1984), he referred to this new species in a note in the key to Dufouriini genera: at the couplet for Pandelleia, one reads (Crosskey, 1984: 238): "Two species: also an undescribed species from Mauritius (...)". The Afrotropical Pandelleia now comprises three species.

\section{MATERIAL AND METHODS}

The type material is deposited at the Natural History Museum, London, United Kingdom (NHMUK). The labels of type material are represented with quotes (") to indicate the same label, slash (/) to line break, and semicolon to indicate a new label. 
Table 1. Species of Pandelleia with their recorded distribution ( ${ }^{*}=$ type species).

\begin{tabular}{|c|c|c|}
\hline Species & Distribution & References \\
\hline P. albipennis Villeneuve, 1934 & Israel & Villeneuve (1934) \\
\hline P. dimorphia (Curran, 1939) & $\begin{array}{l}\text { D.R. Congo, Uganda, Tanzania } \\
\text { Burundi } \\
\text { South Africa }\end{array}$ & $\begin{array}{l}\text { Emden (1945) } \\
\text { Mesnil (1952) } \\
\text { Curran (1939) }\end{array}$ \\
\hline P. ornata (Rohdendorf, 1923) & Uzbekistan & Rohdendorf (1923) \\
\hline P. otiorrhynchi Villeneuve, 1922 & $\begin{array}{l}\text { Germany } \\
\text { France, Switzerland }\end{array}$ & $\begin{array}{l}\text { Villeneuve (1922) } \\
\text { Mesnil (1975) }\end{array}$ \\
\hline P. pilicauda Mesnil, 1975 & Mongolia & Mesnil (1975) \\
\hline P. pschorni Mesnil, 1963 & Japan & Mesnil (1963) \\
\hline P. sexpunctata (Pandellé, 1896)* & $\begin{array}{l}\text { France } \\
\text { Spain } \\
\text { Russia } \\
\text { Armenia, Azerbaijan } \\
\text { Turkmenistan, Uzbekistan }\end{array}$ & $\begin{array}{l}\text { Pandellé (1896) } \\
\text { Herting (1969) } \\
\text { Belanovsky (1937) } \\
\text { Draber-Monko (1985) } \\
\text { Rohdendorf (1923) }\end{array}$ \\
\hline P. translucens (Mesnil, 1959) & Tanzania & Mesnil (1959) \\
\hline
\end{tabular}

Male and female terminalia were put into $10 \%$ solution of $\mathrm{KOH}$ for four minutes in boiling water, followed by neutralization in 5\% acetic acid, and then cleared and washed with distilled water. The terminalia were examined on temporary slides with glycerin, and subsequently stored in plastic microvials with glycerin and attached to the respective specimen. The photographs were made by a digital camera Leica DFC420 attached to a stereomicroscope Leica MZ16. Images were captured with the software Leica LAS v4.1 and then stacked and scaled using the software Helicon Focus v5.3.14. Photographs were edited using the software Adobe Photoshop CS6, and line drawings were prepared and edited in Adobe Illustrator CS6. All plates were prepared in Adobe Illustrator CS6. The terminology of adult morphology followed Cumming \& Wood (2017).

\section{RESULTS}

\section{Pandelleia Villeneuve, 1907}

Diagnosis: All the species hitherto known from Pandelleia are characterized by: body yellow to dark brown in ground color; arista pubescent; occiput, in both sexes, completely covered by black hair-like setae, except for $P$. dimorphia (Curran, 1939); anepimeral seta absent; vein $M$ ending at $\mathrm{R}_{4+5}$ and forming a sometimes long petiole; pair of small round dark brown spots on abdominal syntergite I + II, tergites III and IV, and sometimes on the V; females with the $6^{\text {th }}$ and $7^{\text {th }}$ segment tubular and anteriorly directed.

\section{Pandelleia crosskeyi sp. nov. (Figs. 1-3)}

Type locality: Mauritius, Corps de Garde, Macchabee Forest.

Type material examined: Holotype male (NHMUK) labelled as (Fig. 1D): "Holotype; MAURITIUS: Corps de Garde, / 4.vi.1971 / A.M. Hutson col. B.M.1971-346; to
2,200'; Holotype ơ / Pandelleia mauritiana / sp.n / R.W. Crosskey;"; "Pandelleia crosskeyi/ Santis, M. det. /2015"; "Holótipo" [red label with black borders]; "NMHUK 013933009". Specimen dry pinned.

Paratypes (NHMUK): 2 female paratypes labeled as: "Paratype; MAURITIUS: Macchabee Forest, / 1.vi.1971 / A.M. Hutson col. B.M.1971-346; Paratype $\$$ / Pandelleia mauritiana / sp.n / R.W. Crosskey;"; "Parátipo" [green label with black borders]. 2 male paratypes: "Paratype; MAURITIUS: Corps de Garde, / 4.vi.1971 / A.M. Hutson col. B.M.1971-346; to 2,200'; Paratype o" / Pandelleia mauritiana / sp.n / R.W. Crosskey;"; "Parátipo" [green label with black borders]. 1 female Paratype: "Paratype; MAURITIUS: Corps de Garde, / 4.vi.1971 / A.M. Hutson col. B.M.1971-346; to 2,200'; Paratype female / Pandelleia mauritiana / sp.n / R.W. Crosskey;"; "Parátipo” [green label with black borders]. All paratypes dry pinned.

Diagnosis: This new species readily differs from all other species in the genus by the following combination of characters: abdomen lacking the pair of small, round and dark brown spots; vein $M$ ending in $\mathrm{R}_{4+5}$ at a $90^{\circ}$ angle; female with dark brown scutellum; smallest species of the genus, with a length mean of $2.55 \mathrm{~mm}$, all other Pandelleia species are bigger, ranging between $3 \mathrm{~mm}$ to $5 \mathrm{~mm}$.

Description: Male. Figs. 1A-C, 2A, B. Body length: $2.55 \mathrm{~mm}$, wing length: $2.42 \mathrm{~mm}$.

Coloration (Figs. 1A-C): Head dark brown with ocellar triangle dark brown and median region of occiput with two vertical black bands. Fronto-orbital plate dark brown, with light grey pruinosity, parafacial with silver pruinosity. Postpedicel dark brown, with distal $1 / 4$ dark orange, scape, pedicel, and arista entirely dark brown. Genal groove dark yellow with black setulae. Genal dilation and face light brown. Occiput dark brown. Palpus yellow and labella orange. Scutum dark brown. Halter stem dark yellow and knob dark brown. Calypters light brown. Tegula dark brown and basicosta light brown. Legs brownish. Abdomen without pruinosity, light yellow, but syntergite I + II light brown dorsally, tergites III ( $1 / 4$ light brown) and IV ( $1 / 2$ light brown) with dark brown median vittae on posterior margin and tergite $\mathrm{V}$ entirely dark brown.

Head (Figs. 1B, C): Holoptic. Eye bare. Inner vertical setae convergent and outer vertical setae divergent, both well developed. Ocellar setae proclinate. Postocellar setae developed, proclinate. Frons at its narrowest point about $0.5 \mathrm{X}$ as wide as vertex in dorsal view. Frontal setae 5-6, descending to level of antennal insertion. Orbital setae absent. Frontal vitta narrow. Fronto-orbital plate slightly curved in profile. Postpedicel oval, $0.12 \mathrm{~mm}$ in length, pedicel $1 / 4$ the length of postpedicel. Arista pubescent, thickened on basal $1 / 5$. Parafacial entirely bare. Facial carina absent. Vibrissa well differentiated from adjacent seta, inserted slightly above lower facial margin. Subvibrissal setae 1-2. Facial ridge with one setulae near the vibrissa insertion. Gena height $1 / 5$ of eye height. Genal dila- 
tion covered by fine black setulae. Lower facial margin not visible in profile. Occiput with black setulae. Palpus filiform, nearly as long as prementum, with setulae only apically. Labellum small.
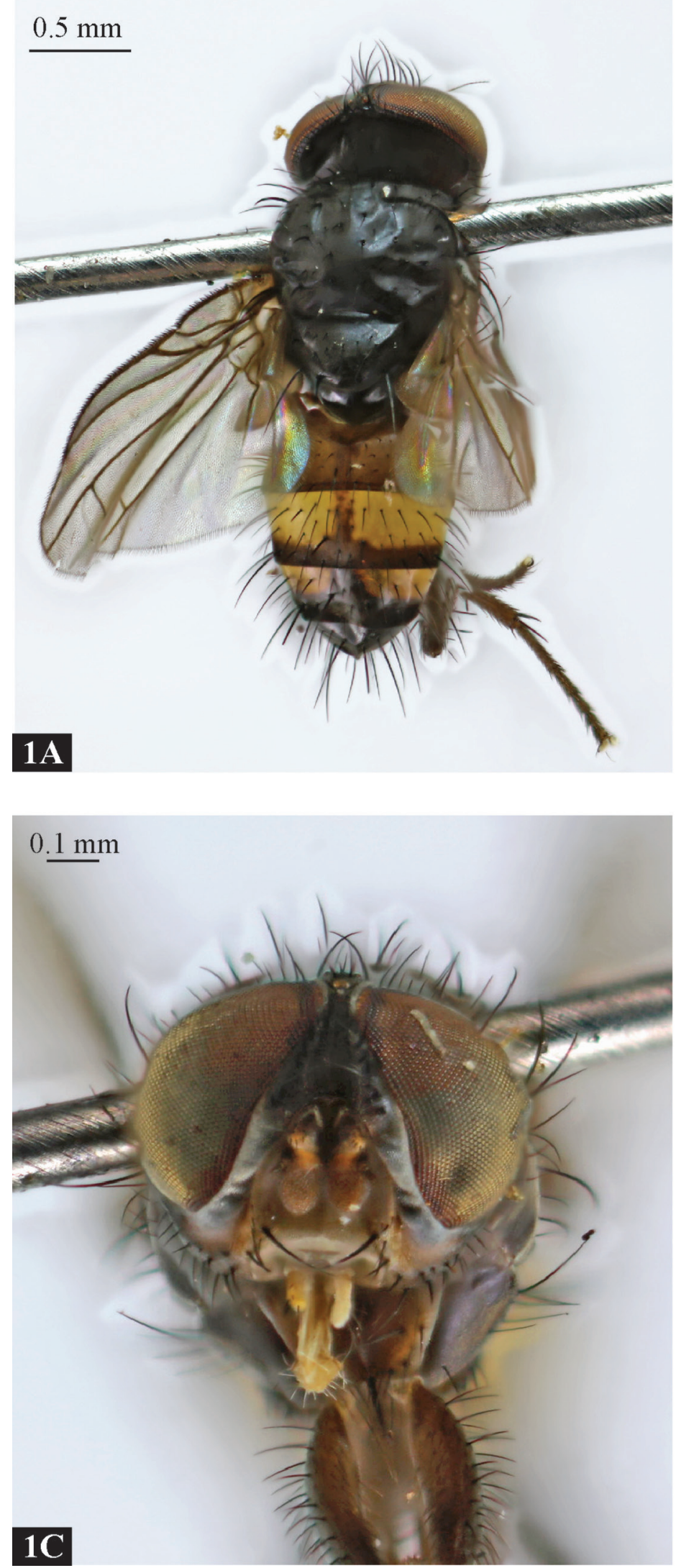

Thorax (Figs. 1A, B): Acrostichal setae $2+3$, dorsocentral setae $2+2$, intra-alar setae $2+2$ (post sutural longer), postalar setae $1+1$. Post-pronotal lobe with 2 setae. Notopleural setae 2. Proepimeral seta 1. Proepisternal
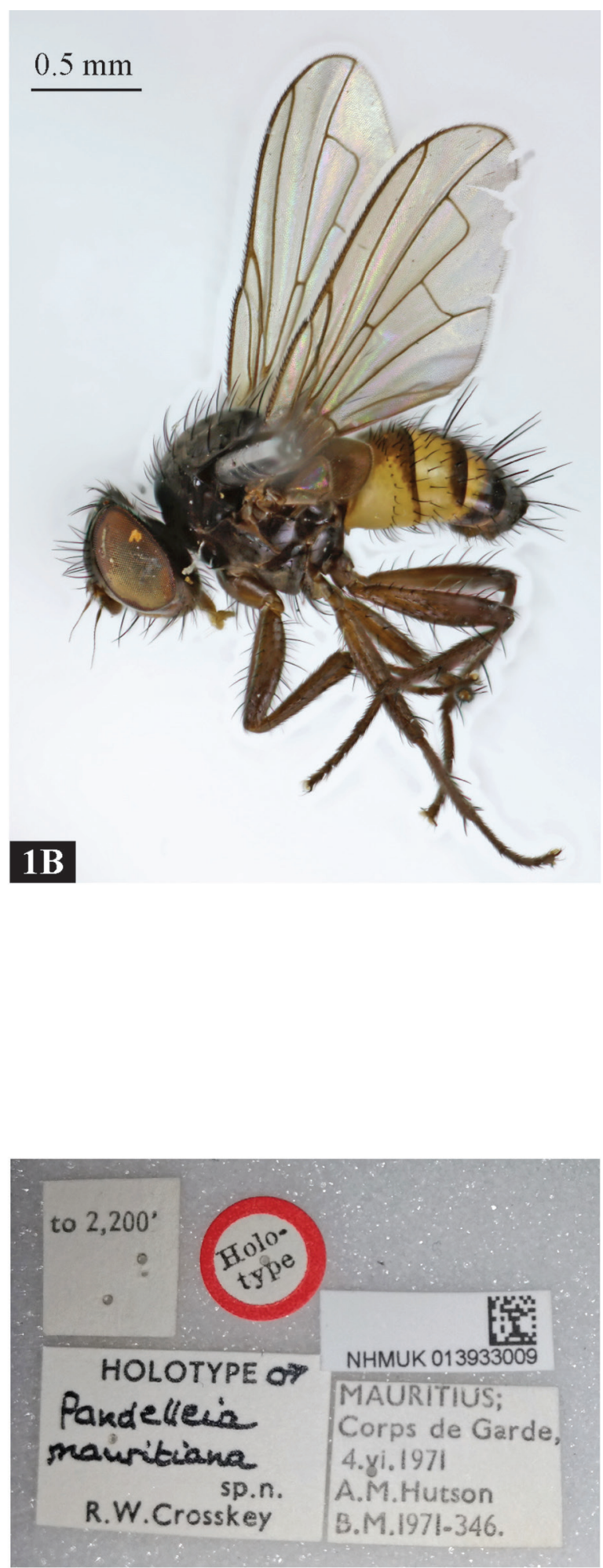

\section{$1 D$}

Figure 1. (A-D) Pandelleia crosskeyi sp. nov., male, holotype. (A) Dorsal habitus; (B) Lateral habitus; (C) Head, frontal view. (D) holotype labels. 


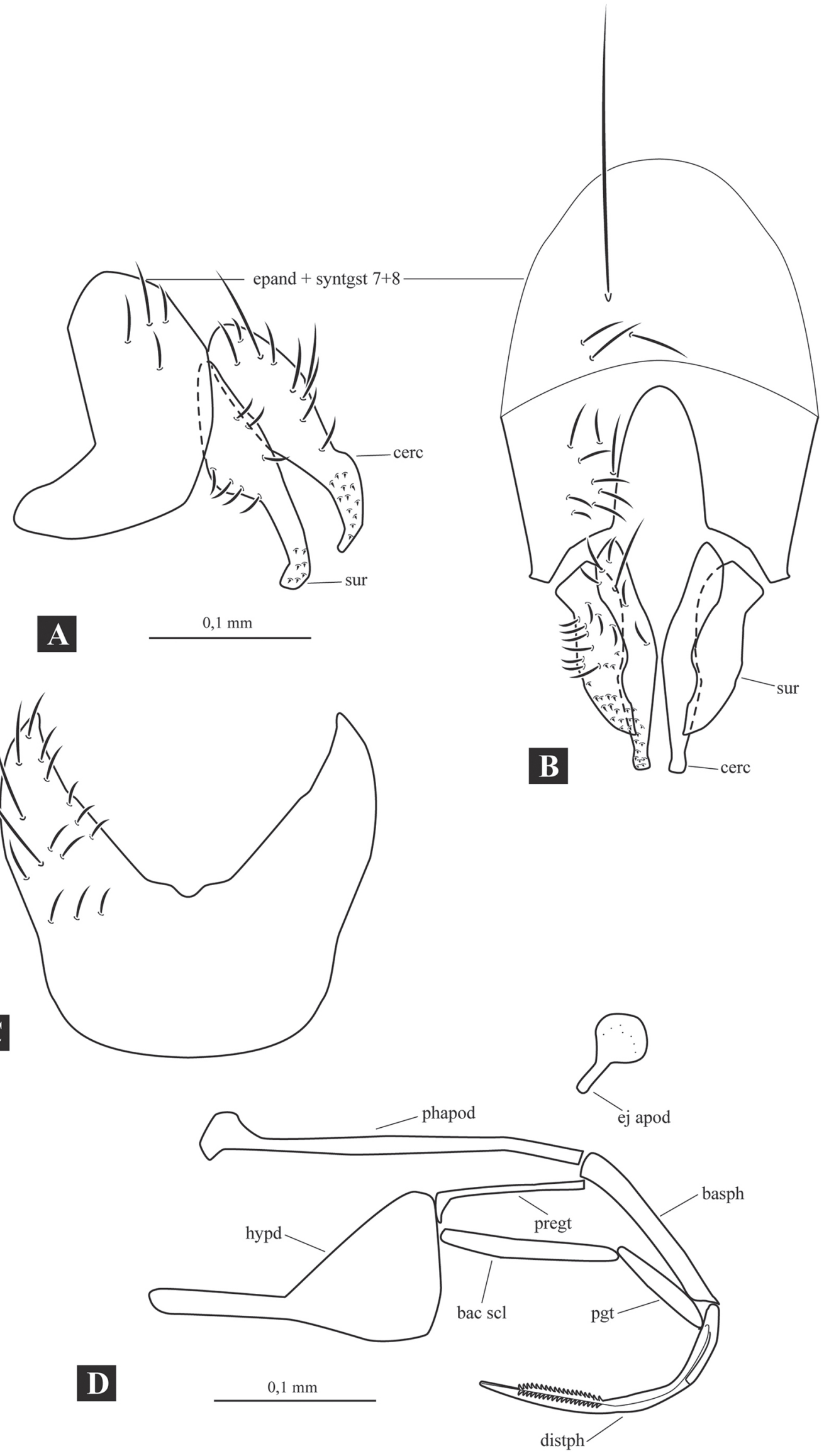

Figure 2. (A-D) Pandelleia crosskeyi sp. nov., male terminalia, paratype. (A) Epandrium + syntergosternite $7+8$, cercus, surstylus, lateral view; (B) Epandrium + syntergosternite $7+8$, cercus, surstylus, lateral view; (C) Sternite 5; (D) Hypandrium, bacilliform sclerite and aedeagus, lateral view. (Abbreviations: bac scl = bacilliform sclerite; basph = basiphallus; cerc = cercus; distph = distiphallus; epand = epandrium; ej apod = ejaculatory apodeme; hypd = hypandrium; $\mathrm{pgt}=$ postgonite; phapod = phallapodeme; pregt = pregonite; sur = surstylus; syntgst = syntergosternite). 

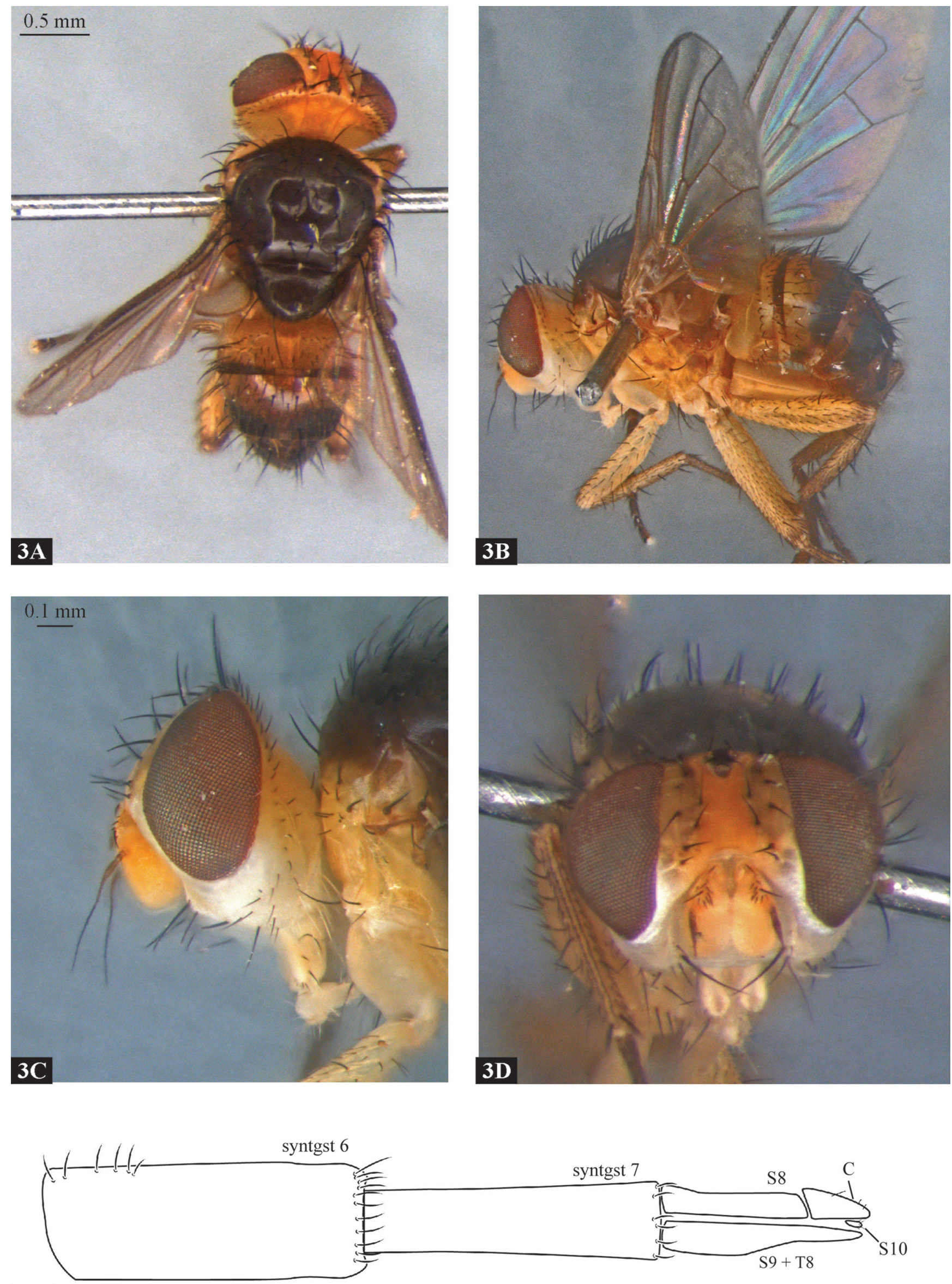

3E

$0,5 \mathrm{~mm}$

Figure 3. (A-E) Pandelleia crosskeyi sp. nov., female, paratype. (A) Dorsal habitus; (B) Lateral habitus; (C) Head, lateral view; (D) Head, frontal view; (E) Female terminalia, lateral view. (Abbreviations: $C=$ cercus; syntgst $=$ syntergosternite; $S=$ sternite; $T=$ tergite). 
seta 1. Prosternum bare. Scutellum with 1 pair of basal, lateral, apical and discal (weak) setae. One short anepimeral seta, without adjacent setulae. Meron with 2 setae. Anatergite and katepimeron bare. Katepisternum with 1 anterior and 1 posterior setae. Posterior spiracle with anterior and posterior lappets subequal-sized.

Wing (Figs. 1A, B): Hyaline. Costal spine absent. Base of $R$ vein with 1 seta dorsally. $\mathrm{R} 1$ and $\mathrm{CuA}_{1}$ bare. Cell $\mathrm{r}_{4+5}$ petiolate, $1.8-2 \mathrm{X}$ as long as postangular section of $M$, ending in $\mathrm{R}_{4+5}$ at a $90^{\circ}$ angle.

Legs (Fig. 1B) Fore femur with row of posterodorsal and posteroventral setae; fore tibia with 1 seta on median $1 / 3$, 1 seta on apical $1 / 3$ and 2 preapical setae on posterodorsal, and 2 preapical setae on anteroventral surface. Mid femur with 1 supramedian seta on anteroventral and on posteroventral, 1 supramedian anterior seta, and 2 preapical setae on posterodorsal surface; mid tibia with 1 anterodorsal seta at apical third, 1 anterodorsal seta on median third, 2 posterodorsal setae on apical third and proximal 1/3, 1 preapical seta on ventral and anterodorsal surfaces. Hind femur with a row of posterodorsal and anterodorsal setae, and 2 preapical anterodorsal setae; hind tibia with 2 median anterodorsal seta, 2 median posterodorsal seta and 1 preapical seta on posteroventral, ventral and on posterodorsal surfaces. Postmetacoxal area membranous.

Abdomen (Figs. 1A, B): Short-ovate in shape. Mid-dorsal depression on syntergite I + II confined to about anterior $1 / 2$. Syntergite I + II without setae. Tergite III with 1 lateral marginal and 1 median marginal pair of setae. Tergite IV with 1 or 2 lateral marginal and 1 median marginal pair of setae. Tergite $V$ with a row of discal setae. Sternites visible from below.

Male terminalia (Figs. 2A, B): Sternite 5 without transversal membranous band, weakly developed lobes and with setulae only on posterior margin. Sternite 6 symmetric. Tergite 6 completely fused with syntergosternite $7+8$, with 1 long seta in the center and some setulae posteriorly; this complex is fused with epandrium, which is short and convex, with a visible suture line (Fig. 2A). Ejaculatory apodeme small, rounded. Cerci broad, tapered and well separated in posterior view, curved, with the apex somewhat rounded and directed anteriorly, in lateral view. Surstyli narrow, strongly convex distally, slightly dilated, curved, and with tip narrowed internally in profile. Baciliform sclerite rod-like. Hypandrial arm absent (i.e., undistinguished), hypandrial apodeme undifferentiated with central plate. Epiphallus present. Pregonite narrow with tip rounded, articulated anteriorly with hypandrium. Postgonite rod-like and bare. Basiphallus attached to distiphallus by flexible membrane. Basiphallus elongated, almost as long as distiphallus. Distiphallus with dorsal sclerite extension fused with the middle bar.

Females (Figs. 3A-E) Body length: $2.53 \mathrm{~mm}$, wing length: $2.4 \mathrm{~mm}$.
Differ from male as follows: Dichoptic. Frons at its narrowest point about $2 \mathrm{X}$ as wide as vertex in dorsal view. Frontal vitta dark yellow. Fronto-orbital plate and occiput yellow. Parafacial, gena and face whitish. Antenna pale yellow, arista dark brown. Postpedicel with $0.24 \mathrm{~mm}$ in length. Gena with $0.16 \mathrm{~mm}$ in length. Palpus and labellum whitish to pale yellow. Thorax yellow, but scutum, scutellum, katatergite, anatergite and meron dark brown. Legs pale yellow, but tarsi (entirely) and mid and hind femur (distal 1/6) dark brown. Halter yellow. Abdomen yellow, but syntergite I + II with light brown thin band on posterior margin, tergites III and IV with larger band on posterior margin ( $1 / 4$ and $1 / 2$, respectively), and tergite $V$ with median dark brown vitta.

Female terminalia (Fig. 3E): Syntergosternite 6 and syntergosternite 7 completely fused with each other, forming a long tube anteriorly directed, both with setulae surrounding the posterior, with setulae on anterodorsal portion only in syntergosternite 6 . Sternite 8 elongate. Sternite 9 (lingulae sec Herting, 1957) elongate with tip narrowed posteriorly, and fused with tergite 8 . Sternite 10 sub-circular. Cercus elongate and narrowed posteriorly.

Etymology: Species named in honor of the late Dr. Roger Crosskey (1930-2017), former curator of Diptera at the Natural History Museum in London, who first recognized this new species. Noun in genitive singular.

\section{Geographical distribution: Mauritius.}

Remarks: Campogastrina was a subtribe of Mesnil (1975) that included, besides Pandelleia and Afrophasia (= Pandelleia), other genera that are now considered as Dufouriini: Rondania Robineau-Desvoidy, 1850; Microsoma Macquart, 1855; and Chaetoptilia Rondani, 1862. In couplet 4 of the key for Campogastrina by Mesnil (1975) used to differentiate Afrophasia (= Pandelleia) and Pandelleia, this new species runs to Afrophasia, which was then formed by $P$. dimorphia, $P$. translucens and P. pschorni. Pandelleia crosskeyi sp. nov., shares the following traits with these species: abdomen without pruinosity; only 2 setae in the meron; wing with tegula deep black; basicosta yellow and only 1-2 setulae at the base of $\mathrm{R}_{4+5}$.

Finally, as a historical information, Dexia dejeanii Robineau-Desvoidy, 1830 would it be the first Dexiinae from Mauritius; however as its type is lost and it is currently considered an unplaced Tachinidae (O'Hara \& Cerretti, 2016), Pandelleia crosskeyi is the only valid and recognized Dexiinae from Mauritius.

\section{ACKNOWLEDGMENTS}

We thank the Institute of Biosciences of the University of São Paulo for the logistical support. MDS is indebted to Nigel Wyatt (NHMUK) for facilities and kind assistance during his visit. Financial support from CAPES (MDS scholarship: 88882.333078/2019-01), CNPq (SSN research 
grant: 403165/2016-4, SSN fellowship: 309192/2018-8), and FAPESP (SSN research grants: 2015/10788-0, 2016/50387-7).

\section{AUTHORS' CONTRIBUTIONS}

MDS: identification and illustration of species, writing original draft; SSN: identification of species, writing review and editing. Both authors read and approved the final version of the manuscript.

\section{COMPETING INTERESTS}

The authors have declared that no competing interests exist.

\section{REFERENCES}

Belanovsky, I.D. 1937. Zwei neue Arten von Parasitenfliegen auf Zuckerrübenschädlingen. Travaux du Musée zoologique de l'Académie des Sciences de I'Ukraine, 19: 217-222.

Crosskey, R.W. 1984. Annotated keys to the genera of Tachinidae (Diptera) found in tropical and southern Africa. Annals of the Natal Museum, 26: 189-337.

Cumming, J.M. \& Wood, D.M. 2017. Adult morphology and terminology. In: Kirk-Spriggs, A.H. \& Sinclair, B.J. (Eds.). Manual of Afrotropical Diptera. Vol. 1. Introducion and family keys. Pretoria, South African National Biodiversity Institute Graphics \& Editing. p. 89-133.

Curran, C.H. 1939. African Tachinidae. II. American Museum Novitates, 1022: 1-5.

Draber-Monko, A. 1985. Redescription of Pandelleia maculata (Belanovskij) (Diptera: Tachinidae). Israel Journal of Entomology, 19: 51-54.

Emden, F.I. van. 1945. Keys to the Ethiopian Tachinidae. - I. Phasiinae. Proceedings of the Zoological Society of London, 114(1944): $389-436+3$ pls.

Herting, B. 1957. Das weibliche Postabdomen der calyptraten Fliegen (Diptera) und sein Merkmalswert für die Systematik der gruppe. Zeitschrift für Morphologie und Ökologie der Tiere, 45: 429-461.
Herting, B. 1969. Records of Tachinidae (incl. Rhinophoridae) and Oestridae (Diptera) from Southern Spain with descriptions of two new species. Entomologiske Meddelelser, 37(3): 192-210.

Herting, B. \& Dely-Draskovits, Á. 1993. Family Tachinidae. In: Soós, Á. \& Papp, L. (Eds.). Catalogue of Palaearctic Diptera. Volume 13. AnthomyiidaeTachinidae. Budapest, Hungarian Natural History Museum. p. 118-458.

Mesnil, L.P. 1952. Seconde note préliminaire sur les Tachinaires du Congo Belge. Bulletin de I'Institut royal des sciences naturelles de Belgique. Entomologie \& Biologie, 28(2): 1-15.

Mesnil, L.P. 1959. Tachinidae d'Afrique orientale (Dipt.). Stuttgarter Beiträge zur Naturkunde, Serie A: Biologie, 23: 1-31.

Mesnil, L.P. 1963. Nouveaux Tachinaires de la Region Palearctique principalement de I'URSS et du Japan. Bulletin de I'Institut royal des sciences naturelles de Belgique. Entomologie \& Biologie, 39(24): 1-56.

Mesnil, L.P. 1975. 64g. Larvaevorinae (Tachininae). In: Lindner, E. (Ed.). Die Fliegen der palaearktischen Region, 10 (Lieferung 309). Stuttgart, E. Schweizerbart'sche Verlagsbuchhandlung. p. 1305-1384.

0'Hara, J.E. \& Cerretti, P. 2016. Annotated catalogue of the Tachinidae (Insecta, Diptera) of the Afrotropical Region, with the description of seven new genera. ZooKeys, 575: 1-344.

O'Hara, J.E.; Henderson, S. \& Wood, D.M. 2020. Preliminary checklist of the Tachinidae (Diptera) of the world. Version 2.1. http://www.nadsdiptera. org/Tach/WorldTachs/Checklist/Worldchecklist.html. Access: 06/12/2020.

Pandellé, L. 1896. Etudes sur les Museides de France. Revue d'Entomologie, Caen, 15: 1-230.

Rohdendorf, B.B. 1923. Zur Kenntnis der Gattung Syntomogaster Sch. Zoologischer Anzeiger, 57: 24-28.

Shima, H. 2015. A Host-parasite catalog of Tachinidae (Diptera) of Japan. Makunagi/Acta Dipterologica, 26: 9-19.

Thébaud, C.; Warren, B.H.; Cheke, A.C. \& Strasberg, D. 2009. Mascarene Islands, biology, pp. 612-619. In: Gillespie, R.G. \& Clague, D.A. (Eds.). Encyclopedia of islands. Berkeley, University of California Press.

Thiem, H. 1922. Zur Biologie und Bekämpfung des gefurchten Dickmaulrüßlers (Otiorrhyncus sulcatus F.). Zeitschrift für Angewandte Entomologie, 8(2): 389-402.

Villeneuve, J. 1922. Myiodaires supérieurs Paléarticques nouveaux. Annales des sciences naturelles Zoologie, 5(10): 337-342.

Villeneuve, J. 1934. Myodaires supérieurs peu connus ou inédits de la Palestine. Konowia, 13: 54-57. 